\title{
Increased prevalence of group A B-hemolytic streptococcus among an ethnic population in Kyrgyzstan detected by the rapid antigen detection test
}

\author{
NAZGUL A. OMURZAKOVA ${ }^{1,7}$, YOSHIHISA YAMANO ${ }^{1}$, TOMOO SATO ${ }^{1}$, TOSHIHIKO IZUMI ${ }^{1}$, \\ KAZUKO AZAKAMI $^{1}$, DAISUKE HASEGAWA ${ }^{1}$, RYOJI FUJII ${ }^{1}$, NAOKO YAGISHITA ${ }^{1}$, SATOKO ARATANI ${ }^{1}$, \\ ZUHRA S. KABAEVA ${ }^{7}$, MIRSAID M. MIRRAKHIMOV ${ }^{7}$, MASAHIRO KAMI $^{4}$, IKURO MARUYAMA ${ }^{5}$, \\ MITSUHIRO OSAME ${ }^{5}$, SHUNPEI YOKOTA ${ }^{6}$, KUSUKI NISHIOKA ${ }^{1}$ and TOSHIHIRO NAKAJIMA ${ }^{1,2,3}$ \\ ${ }^{1}$ Institute of Medical Science, St. Marianna University, Kawasaki; ${ }^{2}$ Choju Medical Institute, Fukushimura Hospital, \\ Toyohashi; ${ }^{3}$ Center for Rheumatology and Joint Diseases, Misato Marine Hospital, Kochi; ${ }^{4}$ Institute of Medical Science, \\ University of Tokyo, Tokyo; ${ }^{5}$ Kagosima University, Kagosima; ${ }^{6}$ Yokohama City University, Yokohama, Japan; \\ ${ }^{7}$ National Center of Cardiology and Internal Medicine, Bishkek, Kyrgyzstan
}

Received June 24, 2008; Accepted September 17, 2008

DOI: $10.3892 / \mathrm{mmr} 00000043$

\begin{abstract}
The incidence of rheumatic fever (RF) has markedly increased in the last 10 years in Kyrgyzstan. Therefore, investigating the prevalence of group A B-hemolytic streptococcus (GABHS), which is the cause of RF, in the Kyrgyzstan population is crucial. We studied 189 subjects: 59 children [29 with RF and/or rheumatic heart disease (RHD)] and 130 adults (15 with RHD). The average age of the subjects was $41.0 \pm 10.0$ years (range 8 months to 72 years). A general clinical examination and medical history including eating habits was carried out. The prevalence of GABHS was tested using the highly sensitive rapid antigen detection test (RADT) to detect the outcrop of streptococcus antigen in smears taken from the mucosal surface of the tonsils or the back of the throat. GABHS antigen was positive in 70 of a total 189 subjects $[37.0 \% ; 22 / 59$ children $(37.2 \%), 48 / 130$ adults $(36.9 \%)]$. In patients with RF/RHD $(n=44)$, GABHS was positive in 14 subjects $[31.8 \% ; 8 / 29$ children $(27.6 \%), 6 / 15$ adults (40.0\%)]. Thirty-two subjects with RF/RHD had frequent episodes of tonsillopharyngitis. In subjects without RF/RHD ( $\mathrm{n}=145)$, GABHS was positive in 56 subjects [38.6\%; $14 / 30$ children $(46.6 \%), 42 / 115$ adults $(36.5 \%)]$. Thirty of these subjects had frequent episodes of tonsillopharyngitis. Of the 130 adults, the most-consumed dairy products included yoghurt $(n=115 ; 88.4 \%)$, milk kasha $(n=75 ; 57.7 \%)$ and milk
\end{abstract}

Correspondence to: Dr Toshihiro Nakajima, Institute of Medical Science, St. Marianna University, School of Medicine, 2-16-1 Sugao, Miyamae-ku, Kawasaki, Kanagawa 216-8512, Japan

E-mail: nakashit@marianna-u.ac.jp

Key words: group A B-hemolytic streptococcus, rheumatic fever, rheumatic heart disease, rapid antigen detection test, carrier $(\mathrm{n}=40 ; 30.7 \%)$. Of the 115 subjects in the yoghurt-consuming group, $44(38.2 \%)$ had positive results for GABHS. In the nonyoghurt-consuming group, $4 / 15$ subjects $(26.6 \%)$ had positive results for GABHS. Using RADT for GABHS, a high prevalence of GABHS antigen was detected not only in patients with RF/RHD, but also in the healthy population (without $\mathrm{RF} / \mathrm{RHD})$. The low GABHS prevalence in children with RF/ RHD (27.6\%) was probably due to corresponding antibiotic therapy. In conclusion, the high prevalence of GABHS is one of the main reasons for the rapid increase in RF/RHD in Kyrgyzstan, and RADT would be an effective tool for its detection.

\section{Introduction}

Acute rheumatic fever (ARF) remains one of the key problems facing the public health services of many countries worldwide. The study of rheumatic fever (RF), rheumatic heart disease (RHD) and streptococcal infection of the upper respiratory tract is of great value to developing countries, whose populations comprise $2 / 3$ of the world population $(1,2)$. A review of the available statistics reveals that from 1960 to 1970 in the (former) USSR, the rate of RF incidence was 20-30 cases per 1000 population. However, during that period morbidity decreased to $2 \%$, and the frequency of the formation of heart defects was $15-30 \%$. The introduction of widespread prevention (regular medical check-ups and improvements in the quality of life of the general population) decreased the incidence of RF to levels found in developed countries, i.e., 0.3-0.8 cases per 1000 population. However, with the dissolution of the USSR at the beginning of the 1990s, the frequency of RF in Kyrgyzstan began to rise. Annual reports on children and adults, produced by rheumatologists between 1998 and 2006 for the public health sector, demonstrated a high incidence of cardiac involvement and high recurrence rates of RF. Among the general population, the incidence of RF/RHD increased by 5.6-6.4 per 1000 population during this period. ARF is a 
Table I. Patient characteristics.

\begin{tabular}{lcccc}
\hline & \multicolumn{2}{c}{ Adults $(\mathrm{n}=130)$} & & Children $(\mathrm{n}=59)$ \\
\cline { 2 - 5 } & $\begin{array}{c}\text { With RF/RHD } \\
(\mathrm{n}=15)\end{array}$ & $\begin{array}{c}\text { Healthy subjects } \\
(\mathrm{n}=115)\end{array}$ & $\begin{array}{c}\text { With RF/RHD } \\
(\mathrm{n}=29)\end{array}$ & $\begin{array}{c}\text { Healthy subjects } \\
(\mathrm{n}=30)\end{array}$ \\
\hline With episodes of tonsillopharyngitis & 8 & 19 & 24 & 19 \\
Without episodes of tonsillopharyngitis & 7 & 96 & 5 \\
\hline
\end{tabular}

$\mathrm{RF}$, rheumatic fever; RHD, rheumatic heart disease; with episodes of tonsillopharyngitis, inflammation of the throat $\geq 2$ times per year.

leading cause of cardiovascular disease among children in the RF/RHD-positive population of Kyrgyzstan. In 2005 alone, there was a distinct increase in cases of RF, from 0.8 to 2.3 per 1000 children $(+151.4 \%)$. Notably, a large number of these patients were from rural areas, which have a primarily ethnic Kyrgyz population. Since RF is one of the complications of tonsillopharyngitis, caused by group A B-hemolytic streptococcus (GABHS), investigating the prevalence of GABHS (streptococcus pyogenes) in Kyrgyzstan is necessary. About $3 \%$ of patients with untreated streptococcal tonsillopharyngitis experience complications from RF $(13,14)$, while RHDs that develop as complications of RF comprise $35-40 \%$ of all hospitalizations for cardiovascular disease.

In this study, we investigated the prevalence of GABHS using the rapid antigen detection test (RADT) (QuickVue Dipstick Strep A test, Quidel Inc., San Diego, CA, USA) to elucidate the resurgence of RF in Kyrgyzstan. RADT detects the streptococcal GABHS antigen in a smear taken from the surface of the tonsils or back of the throat, and provides results within 5-10 min. Moreover, it has a specificity of $95-100 \%$ and a sensitivity of $75-90 \%(8,9-12,27,28)$. As a result, it has been adopted by many health centers worldwide for the diagnosis of streptococcal pharyngotonsillitis. However, this test has never been used in Kyrgyzstan, which currently employs the culture detection method. This study revealed the high prevalence of GABHS, one of the main causes of RF, among the ethnic population in Kyrgyzstan, and demonstrated that RADT is a useful tool for its rapid diagnosis.

\section{Patients and methods}

Subjects. A total of 189 subjects were examined, 59 children (29 with RF and/or RHD) and 130 adults (15 with RHD) (Table I). Subjects were representative of the ethnic Kyrgyz population, with an average age of $41.0 \pm 10.0$ years (range 8 months to 72 years), and were examined to determine i) the prevalence of GABHS in the adult and child population, ii) the characteristics of the Kyrgyz diet and its influence on the prevalence of GABHS, and iii) the relationship between the prevalence of GABHS and the increase of RF in Kyrgyzstan. Subjects gave their informed written consent for participation in the study.

Research methods. Investigation methods included general clinical examination (complaints, medical history and objective examination of the patient), family history (standards of living and eating habits) and anthropomorphic measurement such as
Table II. Prevalence of GABHS among total no. of subjects.

\begin{tabular}{lccc}
\hline & $\begin{array}{c}\text { With RF/RHD } \\
(\mathrm{n}=44)(\%)\end{array}$ & $\begin{array}{c}\text { Without RF/RHD } \\
(\mathrm{n}=145)(\%)\end{array}$ & $\begin{array}{c}\text { Total } \\
(\mathrm{n}=189)(\%)\end{array}$ \\
\hline $\begin{array}{l}\text { GABHS- } \\
\text { positive }\end{array}$ & $14^{\mathrm{a}}(31.8)$ & $56^{\mathrm{a}}(38.6)$ & $70(37.0)$ \\
$\begin{array}{l}\text { GABHS- } \\
\text { negative }\end{array}$ & $30(68.2)$ & $89(61.4)$ & $119(63.0)$ \\
\hline
\end{tabular}

${ }^{\mathrm{a}} \mathrm{P}=0.41, \chi^{2}$ test of independence. GABHS, group A $\beta$-hemolytic streptococcus; RF, rheumatic fever; RHD, rheumatic heart disease.

growth and body weight. GABHS antigen was detected using RADT (QuickVue Dipstick Strep A test). Samples were collected by physicians from the posterior pharynx and tonsil surfaces of the subjects as recommended by the Infectious Disease Society of America (8).

\section{Results}

Group A $\beta$-hemolytic streptococcus-positive subjects. To detect the GABHS antigen, RADT was used. The test provides rapid and accurate detection of streptococcal pharyngotonsillitis, but has never been employed in Kyrgyzstan. As shown in Table II, 70 of a total 189 subjects $(37.0 \%)$ were positive for the GABHS antigen. In patients with RF/RHD ( $n=44)$, GABHS tested positive in 14 subjects $(31.8 \%)$. Of 145 subjects without RF/RHD, 56 (38.6\%) were positive.

Group A $\beta$-hemolytic streptococcus in children. Each group ( children and adults) was analyzed individually and in detail. As shown in Table III, of a total 59 children, 22 (37.2\%) were positive for the GABHS antigen. Of the 30 children without RF/RHD, 14 (46.6\%) tested positive. Of the 29 children with RF/RHD, only 8 (27.6\%) were positive. Thus, the prevalence of GABHS among children with RF was less than that among children without RF/RHD. The overall high prevalence of GABHS among children (37.2\%) is therefore the result of the large number of healthy subjects carrying this microbe.

Group A $\beta$-hemolytic streptococcus in adults. In the adult group (Table IV), 48 of a total 130 subjects (36.9\%) were positive for GABHS. We inspected only 15 patients with 
Table III. Prevalence of GABHS in children.

\begin{tabular}{lccc}
\hline & $\begin{array}{c}\text { With RF/RHD } \\
(\mathrm{n}=29)(\%)\end{array}$ & $\begin{array}{c}\text { Without RF/RHD } \\
(\mathrm{n}=30)(\%)\end{array}$ & $\begin{array}{c}\text { Total } \\
(\mathrm{n}=59)(\%)\end{array}$ \\
\hline $\begin{array}{l}\text { GABHS- } \\
\text { positive }\end{array}$ & $8^{\mathrm{a}(27.6)}$ & $14^{\mathrm{a}}(46.6)$ & $22(37.2)$ \\
$\begin{array}{l}\text { GABHS- } \\
\text { negative }\end{array}$ & $21(72.4)$ & $16(53.4)$ & $37(62.8)$
\end{tabular}

${ }^{\mathrm{a}} \mathrm{P}=0.21, \chi^{2}$ test of independence.

Table IV. Prevalence of GABHS in adults.

\begin{tabular}{lccr}
\hline & $\begin{array}{c}\text { With RF/RHD } \\
(\mathrm{n}=15)(\%)\end{array}$ & $\begin{array}{c}\text { Without RF/RHD } \\
(\mathrm{n}=115)(\%)\end{array}$ & $\begin{array}{c}\text { Total } \\
(\mathrm{n}=130)(\%)\end{array}$ \\
\hline $\begin{array}{l}\text { GABHS- } \\
\text { positive }\end{array}$ & $6^{\mathrm{a}}(40.0)$ & $42^{\mathrm{a}}(36.5)$ & $48(36.9)$ \\
$\begin{array}{l}\text { GABHS- } \\
\text { negative }\end{array}$ & $9(60.0)$ & $73(63.5)$ & $82(63.1)$ \\
\hline
\end{tabular}

${ }^{\mathrm{a}} \mathrm{P}=0.98, \chi^{2}$ test of independence.

RF/RHD, 6 (40.0\%) of whom were carriers of this pathogenic microbe. Of the 115 subjects without RF/RHD, there were $42(36.5 \%)$ with streptococcus. Thus, the prevalence of GABHS in the adult group with and without RF/RHD was almost equal.

Group A $\beta$-hemolytic streptococcus and tonsillopharyngitis. The prevalence of GABHS in the adult and child groups with and without RF/RHD differed noticeably (Figs. 1 and 2). In adults with RF/RHD ( $n=15), 8$ patients had episodes of tonsillopharyngitis, and 6 of these $(75.0 \%)$ tested positive for GABHS. In adults without RF/RHD ( $\mathrm{n}=115), 19$ patients had episodes of tonsillopharyngitis, and 11 of these $(57.8 \%$ ) tested positive for GABHS. Another 96 subjects from the adult group exhibited no tonsillopharyngitis. Of these, 31 (32.2\%) tested positive for GABHS. Of the children with RF/RHD ( $n=29)$, 24 had and 5 didn't have episodes of tonsillopharyngitis. Of the 24 with episodes of tonsillopharyngitis, only $4(16.6 \%)$ tested positive for GABHS, while $4 / 5$ children without tonsillopharyngitis $(80 \%)$ tested positive. In the children without RF/RHD ( $n=30), 19$ had episodes of tonsillopharyngitis. Six of these $(31.5 \%)$ were positive for GABHS. Of 11 children without tonsillopharyngitis, $8(72.7 \%)$ tested positive for GABHS. In total, 39/70 GABHS-positive subjects $(55.7 \%)$ were absolute asymptomatic carriers .

Role of dairy products in the population. Concomitantly with conducting our examination of the carriers of GABHS, we studied the nutritional habits of the ethnic Kyrgyz population. Among 130 adult subjects, the most-consumed dairy products included yoghurt $(\mathrm{n}=115 ; 88.4 \%)$, milk kasha $(\mathrm{n}=75 ; 57.7 \%)$

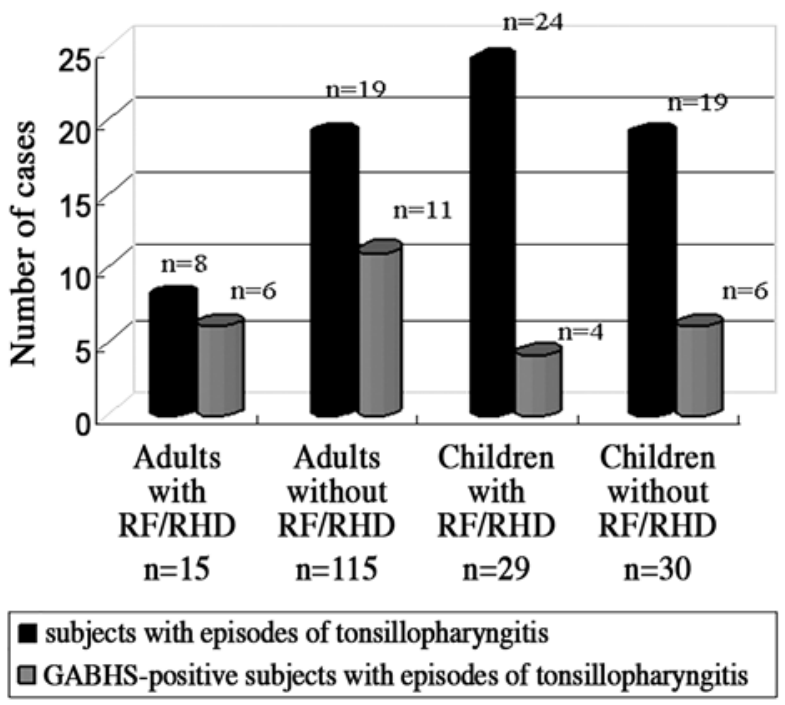

Figure 1. RF/RHD in GABHS-positive and -negative subjects with frequent ( $\geq 2 /$ year) episodes of tonsillopharyngitis. In the adult group with RF/RHD 6/8 patients with episodes of tonsillopharyngitis (75.0\%) were GABHS positive.

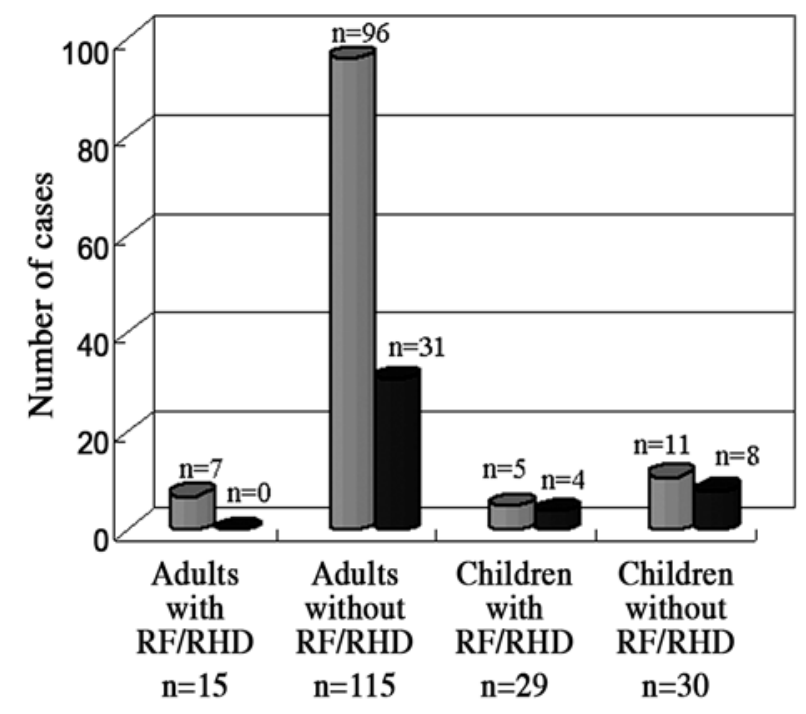

$\square$ subjects without episodes of tonsillopharyngitis

GABHS-positive subjects without episodes of tonsillopharyngitis

Figure 2. RF/RHD in GABHS-positive and -negative subjects subjects without frequent (<2/year) episodes of tonsillopharyngitis. Out of a total $70 \mathrm{GABHS}$ positive subjects, 39 were absolute asymptomatic carriers.

and milk ( $\mathrm{n}=40 ; 30.7 \%$ ). It is well known that streptococcus thrives in dairy products, thus potentially playing a role in streptococcal epidemics. Since dairy products are an integral part of the ethnic Kyrgyz diet, we investigated their effect on the spread of GABHS infection. The most popular product among the population was yoghurt (Fig. 3A). As shown in Fig. 3B, 44/115 in the yoghurt-consuming group (38.2\%) tested positive for GABHS, while 4/15 from the non-yoghurtconsuming group $(26.6 \%)$ were positive, indicating that GABHS is more prevalent among subjects who consume yoghurt than among those who do not. In detail, of the subjects who consumed $<300 \mathrm{ml}$ of yoghurt per day, 35/93 (37.6\%) were positive for GABHS. Of those who consumed 300-501 ml 
Table V. Results of studies from several countries comparing the prevalence of GABHS detected with RADT.

\begin{tabular}{|c|c|c|c|c|c|}
\hline & $\begin{array}{c}\text { Kyrgyzstan } \\
(\%)\end{array}$ & $\begin{array}{c}\text { Belo Horizonte } \\
\text { (Brazil) }(\%)\end{array}$ & $\begin{array}{c}\text { Saudi Arabia } \\
(\%)\end{array}$ & $\begin{array}{c}\text { Tokyo } \\
(\text { Japan) }(\%)\end{array}$ & $\begin{array}{l}\text { Colorado } \\
\text { (USA) }(\%)\end{array}$ \\
\hline GABHS-positive & $70(37.0)$ & 68 (29.6) & $85(24.0)$ & $34(34.0)$ & $210(23.7)$ \\
\hline Total no. subjects & 189 & 229 & 355 & 100 & 887 \\
\hline
\end{tabular}

GABHS, group A ß-hemolytic streptococcus; RADT, rapid antigen detection test.

$\mathbf{A}$

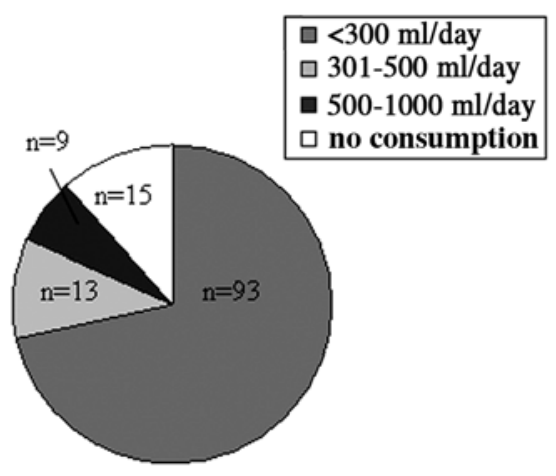

B

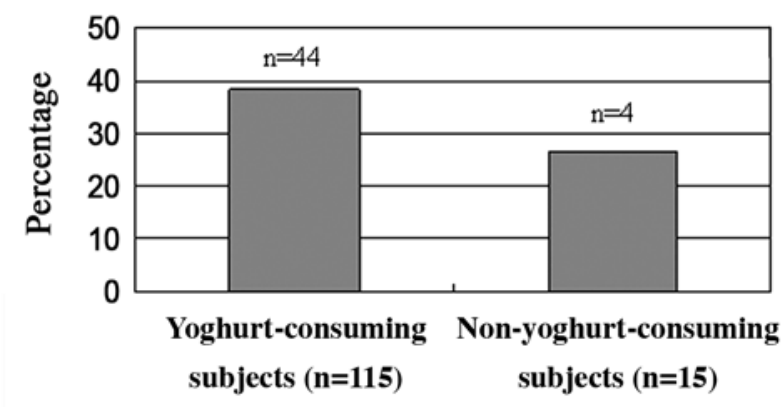

C

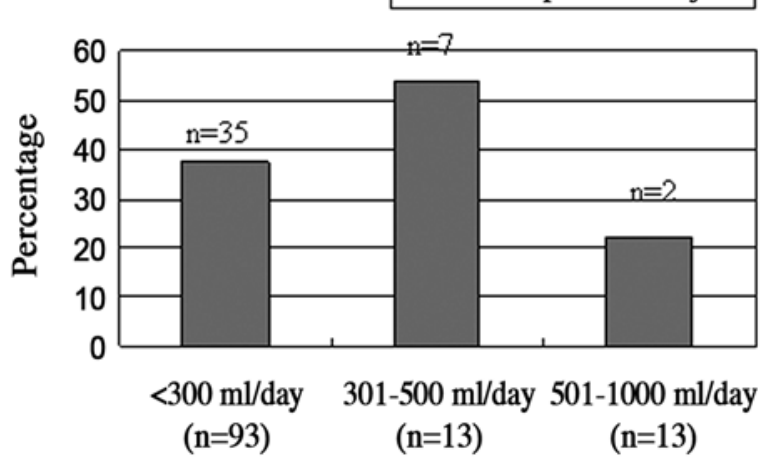

Figure 3. (A) Yoghurt-consumption habits of total no. of adults subjects. (B) Yoghurt-consumption habits of GABHS-positive adults. (C) Yoghurtconsumption habits of GABHS-positive adults according to consumption level.

per day, 7/13 (53.8\%) were positive for GABHS. Lastly, of those who consumed 501-1000 $\mathrm{ml}$ per day, 2/9 (22.2\%) were positive for GABHS (Fig. 3C).

\section{Discussion}

In this study, we examined 59 children, 22 (37.2\%) of whom were positive for GABHS (Table III). Of the 30 children without RF/RHD, 19 had frequent episodes of tonsillopharyngitis ( $\geq 2$ times per year) (Table I) while 14 (46.6\%) tested positive for GABHS. This positive result confirms the transfer of GABHS infection by air, in particular at schools and kindergartens. Notably, the prevalence GABHS in children with RF/RHD was not as high as in those without (27.6\%), possibly due to the effective use of appropriate antibiotics.

Of the total 130 adult subjects, 48 (36.9\%) were positive for GABHS (Table IV). Adult carriers of streptococcus pyogene 6 , of whom 15 (40\%) had RF/RHD, numbered more than the child carriers of RF/RHD. In the adult group with RF/RHD, 8 patients had frequent episodes of tonsillopharyngitis. Of these 8, $6(75.0 \%)$ were GABHS-positive (Fig. 1). This is probably due to the key problem of irregular secondary prophylaxis. However, we cannot exclude a change in the virulence of the streptococcus as, due to treatment with antibiotics, not all patients with RF/RHD were carriers of GABHS. In the adult group without RF/RHD, 42 subjects $(36.5 \%)$ were GABHS-positive (Table IV), and 19 patients had frequent episodes of tonsillopharyngitis. Of these 19, 11 (57.8\%) were GABHS-positive. According to the medical history obtained from the subjects, none had consulted a physician or been administered antibiotics for throat inflammation. In the adult group without RF/RHD and without episodes of tonsillopharyngitis, 31 subjects $(32.2 \%)$ who tested positive for this pathogenic microorganism were determined to be asymptomatic carriers (Fig. 2). Thus, 39 healthy subjects (55.7\%; 31 adults and 8 children) out of the 70 GABHSpositive subjects were absolute asymptomatic carriers, while another $31(44.3 \%)$ had RF/RHD and tonsillopharyngitis. This high percentage of asymptomatic carriers of GABHS within the Kyrgyz population poses a threat, as large numbers of those sensitive to the pathogenic microbe can easily be infected.

It is important to note the nutritional habits of this population. Of the 130 adult subjects, $115(89.0 \%)$ consumed dairy products every day. Indeed, milk products, such as homemade yoghurt, are one of the staples of the ethnic Kyrgyz diet. In the yoghurt-consuming group, $38.2 \%$ of subjects were positive for GABHS versus $26.6 \%$ in the nonyoghurt-consuming group (Fig. 3B). In the group drinking $301-500 \mathrm{ml}$ of yoghurt per day, $53.8 \%$ subjects were GABHS carriers (Fig. 3C). As mentioned above, streptococcus feeds on and grows in dairy products, thereby playing an important 
role in streptococcal epidemics. Although the consumption of yoghurt is healthy, carriers of the pathogenic microbe can infect other individuals through domestically produced dairy products.

As part of the current study, we compared the results of studies using RADT for the etiological diagnosis of acute pharyngitis in several countries (Table V). In an examination of 229 children in Belo Horizonte, Minas Gerais, Brazil, 68 (29.6\%) were GABHS-positive (15). Of 355 patients (aged 4 to $\leq 15$ years) in Saudi Arabia, $24 \%$ of patients proved to be positive (16). In a study conducted at Teikyo University Hospital (Tokyo, Japan), 34/100 patients with pharyngitis $(34 \%)$ were positive (26). A total of 887 throat cultures analyzed at the University of Colorado Health Sciences Center (USA) revealed 210 GABHS-positive cases (23.7\%).

The QuickVue Dipstick Strep A test has shown a high specificity of $100 \%$ and a sensitivity of $94.0 \%$ in some studies (26), but in others a high specificity of $99.4 \%$ and a low sensitivity of $65.6 \%$ (28). Consequently, it is not possible to completely confirm our results regarding the absence of streptococcal infection in the throat of subjects in our Kyrgyz population. According to the American Academy of Pediatrics, the specificity and sensitivity of the test needs to be confirmed by further research using culture detection methods $(8,13,17,27,28)$. However, for the rapid detection of streptococcal tonsillopharyngitis, RADT is a very useful and convenient tool, as demonstrated in this study.

From the results of this study, it is possible to conclude that there is a close correlation between the high prevalence of GABHS and the increase in cases of RF in Kyrgyzstan. In assessing the effects of the prevalence of GABHS on RF, the following issues must be considered: i) a possible change in the virulence of the streptococci, ii) that the transmission of infection can occur through any food product (milk, soup, kasha, etc.), iii) a relatively high population concentration living in respective territories, iv) the periodic recurrence and subsequent disappearance of aggressive streptococcal infection, v) low standards of living and vi) an increase in the population migration. The reasons for the abundance of this pathogenic microbe in Kyrgyzstan remain unknown.

Although ARF as a nosologic unit has precise clinical characteristics, diagnosis of the disease remains a problem as it does not often have distinct clinical symptomatology. Consequently, in some cases, ARF is manifested after heart disease has occurred. Preventive measures are therefore urgently needed. By using RADT in a Kyrgyz population, we were able to detect GABHS carriers and to eradicate the microbe using antibacterial therapy. This preventive measure can play an important role in decreasing the prevalence of streptococcal tonsillopharyngitis, thus limiting the number of individuals suffering from its complications, RH and RHD.

Many cases of RF have been reported in various areas of the USA, Europe and Scandinavia (18-21). At present, it is only in developed countries ( $<20 \%$ of the world population) that the disease is not manifested (22). The annual incidence of RF in developed countries is less than $1.0 / 100000$, but in developing countries there is a far greater range in occurence: 1.0/100000 in Costa Rica, 72.2/100000 in French Polynesia, up to $100 / 100000$ in Sudan, and up to $150 / 100000$ in China. The occurrence of RF in children and teenagers is universally reported. According to the World Health Organisation (WHO), 12 million people suffer from RF worldwide, $2 / 3$ of these children aged 5-15 years. Approximately 300000 people succumb to the disease annually, 2 million people require repeated hospitalization and 1 million are likely to need surgery or medical treatment in the following 5-20 years (3). Significantly, 15.6 million people have RHD worldwide, with 282000 new cases of RF and 233000 deaths attributable to RF or RHD each year (4). Approximately 517000 deaths are recorded each year due to severe streptococcal diseases such as ARF, RHD, post-streptococcal glomerulonephritis and invasive infections. The prevalence of severe GABHS disease is reported to be at least 18.1 million cases, with 1.78 million new ones developing each year (4). Therefore, among human pathogens, GABHS plays a critical role, and its high prevalence is a global problem.

GABHS, which is mainly transferred via the respiratory tract, contact and food, has as its sources of infection ailing individuals as well as asymptomatic carriers. The resulting development of streptococcal pharyngotonsillitis can be lifethreatening (5-7) when early (purulent) and late (not purulent) complications occur. Thus, the increase of RF and prevalence of GABHS remains a grave problem in developing countries. For over 20 years, WHO has recommended the administration of effectively delivered secondary prophylaxis based on a registry of patients from all countries of the world (23). However, certain developing countries have still not implemented effective secondary prophylaxis programs. In Kyrgyzstan, streptococcal infection has increased to epidemic proportions. Systemic antibiotic therapy is not applied when just one parameter of acute pharyngotonsillitis is present (25). Thus, the problem of comparing clinical and laboratory data to substantiate the purpose of systemic antibacterial therapy exists. Modern standards and medical facilities for diagnostics are needed, including ones for the discovery of the serotype of GABHS, medical treatment and preventive RF and RHD methods among the Kyrgyzstan population.

\section{Acknowledgements}

We are grateful to members of Toshi's Laboratory. This study was supported in part by the National Institute of Biomedical Innovation, the Japanese Ministry of Education, Culture, Sports, Science and Technology, the Japanese Ministry of Health, Labour and Welfare, the Kato Memorial Trust for Nanbyo Research, Japan Medical Association, the Nagao Memorial Fund, Kanae Foundation for Life \& Sociomedical Science, Japan Research Foundation for Clinical Pharmacology, the Kanagawa Nanbyo Foundation, Kanagawa Academy of Science and Technology Research Grants, Japan College of Rheumatology, the Nakajima Foundation, the Osaka Foundation for Cancer Research, the Japan Society for the Promotion of Science, The Mishima Kaiun Memorial Foundation, CALPIS Co. Ltd., Mitsui Life Insurance Co. Ltd., the Uehara Memorial Foundation and Takeda Science Foundation, Heiwa Nakajima Foundation, the Sagawa Foundation for Promotion of Cancer Research, the Tokyo biochemical Research Foundation, the Kanagawa HighTechnology Foundation and the Organization of Future of Kids in Silk Road. 


\section{References}

1. World Health Organization: The Atlas of Heart Disease and Stroke. Rheumatic fever and rheumatic heart disease. http://www.who.int/ cardivascular_diseases/resources/atlas/en/, 2004.

2. Dajani A, Taubert K, Ferrieri P, et al: Treatment of acute streptococcal pharyngitis and prevention of rheumatic fever. A statement for health professionals. Pediatrics 96: 758-764, 1995.

3. Rheumatic fever and RHD. Report of a WHO Expert Consultation, Geneva, 29 October-1 November, 2001.

4. Carapetis JR, Steer AC, Mulholland EK and Weber M: The global burden of group A streptococcal diseases. Lancet Infect Dis 5: 685-694, 2005.

5. Spencer RC: Invasive streptococci. Eur J Clin Microbiol Infect Dis 14 (Suppl 1): S26-S32, 1995.

6. Stevens DL: Invasive group A streptococcal disease. Infect Agents Dis 5: 157-166, 1996.

7. Efstratiou A: Group A streptococci in the 1990s. J Antimicrob Chemother 45 (Suppl 1): S3-S12, 2000

8. Bisno AL, Gerber MA, Gwaltney JM, Kaplan EL, Schwartz RH and the Infectious Diseases Society of America: Practice guidelines for the diagnosis and management of group A streptococcal pharyngitis. Clin Infect Dis 15: 113-125, 2002.

9. Miceika BG, Vitous AS and Thompson KD: Detection of group A streptococcal antigen directly from throat swabs with a ten-minute latex agglutination test. J Clin Microbiol 21: 467-469, 1985.

10. Fujikawa $S$ and Ohkuni M: A new latex agglutination test for rapid diagnosis of group A streptococci. Jpn Circ J 50: 25-31, 1986.

11. Gupta R, Rattan A, Prakash K, Talwar GP and Gupta SK: Immunodiagnosis of group-A streptococci by latex agglutination assays with monoclonal or monospecific polyvalent antibodies. Indian J Med Res 97: 25-31, 1993.

12. Fox JW, Cohen DM, Marcon MJ, Cotton WH and Bonsu BK: Performance of rapid streptococcal antigen testing varies by personnel. J Clin Microbiol 44: 3918-3922, 2006.

13. Dajani AS, Bisno AI, Chung KJ, et al: Prevention of rheumatic fever. A statement for health professionals by the Committee on Rheumatic fever, Endocarditis and Kawasaki Disease of the Council on Cardiovascular Disease in the Young, The American Heart Association. Circulation 78: 1082-1086, 1988

14. Stollerman GH: Rheumatogenic and nephritogenic streptococci. Circulation 43: 915-921, 1971.

15. Fontes MJF, Bottrel FB, Fonseca MTM, Lasmar LB, Diamante R and Camargos PAM: Early diagnosis of streptococcal pharyngotonsillitis: assessment by latex particle agglutination test. J Pediatr 83: 465-470, 2007.
16. Abu-Sabaah AH and Ghazi HO: Better diagnosis and treatment of throat infections caused by group A beta-haemolytic streptococci. Br J Biomed Sci 63: 155-158, 2006.

17. Schwartz B, Marcy M, Phillips WR, Gerber MA and Dowell SF: Pharyngitis: principles of judicious use of antimicrobial agents. Pediatrics 101: 171-174, 1998.

18. Bisno AL, Brito MO and Collins CM: Molecular basis of group A streptococcal virulence. Lancet Infect Dis 3: 191-200, 2003.

19. Gibofsky A and Zabriskie JB: Rheumatic fever: etiology, diagnosis and treatment. In: Arthritis and Allied Conditions. A Textbook of Rheumatology. Vol 2. 14th edition. Koopman WJ (ed). Lippincott Williams \& Wilkins, Philadelphia, pp1761-1773, 2001.

20. Schwartz B, Facklam RR and Breiman RF: Changing epidemiology of group A streptococcal infection in the USA. Lancet 336: 1167-1171, 1990.

21. Kaplan EL: Global assessment of rheumatic fever and rheumatic heart disease at the close of the century. Influences and dynamics of populations and pathogens: a failure to realize prevention? Circulation 88: 1964-1972, 1993.

22. Carapetis JR: Rheumatic heart disease in developing countries. N Engl J Med 357: 439-441, 2007.

23. Rheumatic fever and rheumatic heart disease: report of a WHO expert consultation. World Health Organ Tech Rep Ser 923: $1-122,2004$

24. Esposito $\mathrm{S}$ and Blasi F: Aetiology of acute pharyngitis: the role of atypical bacteria. J Med Microbiol 53: 645-651, 2004.

25. Cooper RJ, Hoffman JR, Bartlett JG, et al: Principles of appropriate antibiotic use for acute pharyngitis in adults: background. Ann Intern Med 134: 509-517, 2001.

26. Kawakami S, Ono Y, Yanagawa Y and Miyazawa Y: Basic and clinical evaluation of the new rapid diagnostic kit for detecting group A streptococci with the immunochromatographical method. Rinsho Biseibutshu Jinsoku Shindan Kenkyukai Shi 14: 9-16, 2003.

27. Gieseker KE, Roe MH, MacKenzie T and Todd JK: Evaluating the American Academy of Pediatrics diagnostic standard for streptococcus pyogenes pharyngitis: backup culture versus repeat rapid antigen testing. Pediatrics 111: e666-e670, 2003.

28. Van Limbergen J, Kalima P, Taheri S and Beattie TF: Streptococcus $\mathrm{A}$ in pediatric accident and emergency: are rapid streptococcal tests and clinical examination of any help? Emerg Med J 23: 32-34, 2006. 